\title{
Advances in diagnosis and treatment of eosinophilia
}

\section{Citation}

Sheikh, Javed, and Peter F Weller. 2009. Advances in Diagnosis and Treatment of Eosinophilia. Current Opinion in Hematology 16, no. 1: 3-8. doi:10.1097/moh.0b013e32831c841f.

\section{Published Version}

doi:10.1097/MOH.0b013e32831c841f

\section{Permanent link}

http://nrs.harvard.edu/urn-3:HUL.InstRepos:27377110

\section{Terms of Use}

This article was downloaded from Harvard University's DASH repository, and is made available under the terms and conditions applicable to Other Posted Material, as set forth at http:// nrs.harvard.edu/urn-3:HUL.InstRepos:dash.current.terms-of-use\#LAA

\section{Share Your Story}

The Harvard community has made this article openly available.

Please share how this access benefits you. Submit a story.

\section{Accessibility}




\title{
Advances in diagnosis and treatment of eosinophilia
}

\author{
Javed Sheikh ${ }^{\mathrm{a}}$ and Peter F. Weller ${ }^{\mathrm{b}}$ \\ aDivision of Allergy and Inflammation, Harvard Medical School, Beth Israel Deaconess Medical \\ Center, Boston, Massachusetts, USA \\ ${ }^{b}$ Divisions of Allergy and Inflammation and Infectious Diseases, Harvard Medical School, Beth \\ Israel Deaconess Medical Center, Boston, Massachusetts, USA
}

\begin{abstract}
Purpose of review-Hypereosinophilic syndromes (HESs) are disorders characterized by sustained blood or tissue hypereosinophilia or both with subsequent damage to various organs due to eosinophilic infiltration and release of mediators. HES are now recognized to include varied eosinophilic disorders for some of which there are recent insights into their pathogenesis and targeted treatment.
\end{abstract}

Recent findings-Studies have helped delineate two subtypes of HES: the myeloproliferative variants of HES and the lymphocytic variants of HES. Many, but not all, myeloproliferative-HES patients have interstitial deletions on chromosome 4q12 that lead to fusion of the FIP1-like 1 and platelet-derived growth factor receptor a genes, with the fusion product encoding a protein that has constitutive tyrosine kinase activity. Lymphocytic-HES is a primary lymphoid disorder characterized by nonmalignant expansion of a T-cell population able to produce eosinophilopoietic cytokines, with the T-cell population being identified by flow cytometry or reverse transcriptase-PCR for T-cell receptor usage or both. Other HES subtypes are of uncertain causes and are included in recent diagnostic algorithms for the spectrum of HES.

Summary-The contemporary definition of the hypereosinophilic syndromes encompasses a range of eosinophilic disorders characterized by chronic blood hypereosinophilia often with eosinophil-mediated damage to various organs.

\section{Keywords}

chronic eosinophilic leukemia; eosinophilia; eosinophils; hypereosinophilic syndrome; imatinib

\section{Introduction}

Eosinophilia, with elevations of blood or tissue eosinophil levels or both, can occur with atopic diseases, drug hypersensitivity reactions, certain malignancies, connective tissue disorders and helminthic parasitic infections [1-3]. When an underlying allergic, parasitic or other cause cannot be identified, the eosinophilic disorder is considered to fall into an umbrella category now known as 'hypereosinophilic syndromes' (HESs) [4]. Originally, HES was called the 'idiopathic hypereosinophilic syndrome' [1], reflecting the fact that little was then known about the pathophysiology of eosinophilia. With recent insights into the causes of some forms of HES and with the recognition that eosinophilic diseases include a

\footnotetext{
(C) 2009 Wolters Kluwer Health|Lippincott Williams \& Wilkins

Correspondence to Javed Sheikh, MD, Division of Allergy and Inflammation, Beth Israel Deaconess Medical Center, Harvard Medical School, One Brookline Place, Suite 623, Brookline, MA 02445, USA, Tel: +1 617278 8100; fax: +1 617 278 8101; jsheikh@bidmc.harvard.edu.
} 
spectrum of disorders, an international working group has endorsed not using the term idiopathic and further recognized that HES should encompass a heterogeneous group of conditions, that is, HESs [3-5]. In addition to what was formally known as idiopathic HES, the HESs include other conditions characterized by tissue-associated eosinophilic inflammation and in most cases peripheral blood eosinophilia, such the Churg-Strauss syndrome (CSS) and the eosinophilic gastrointestinal diseases (EGIDs) [4].

\section{History of the terms hypereosinophilic syndrome and idiopathic hypereosinophilic syndrome}

Descriptions of cases of unexplained hypereosinophilia have been recorded for over 100 years $[1,6]$. Early cases described a variety of presentations, with peripheral eosinophilia, cardiovascular involvement, bone marrow eosinophilia, and features suggestive of collagen vascular disease being variably present, hence terms such as 'eosinophilic leukemia,' 'Loffler's syndrome,' 'Loeffler's fibroplastic endocarditis with eosinophilia,' and 'disseminated eosinophilic collagen disease' were used $[7,8]$. The use of the plural term 'hypereosinophilic syndromes' first occurred in a 1968 review article describing three patients in comparison with previously reported cases, highlighting the heterogeneity of clinical presentations [8].

Diagnostic criteria for the HES were first proposed in 1975 by Chusid et al. [7] in their case series of 14 patients: peripheral blood eosinophilia with absolute eosinophil count greater than 1500 cells/ $\mu 1$ sustained for greater than 6 months; no other evident cause for eosinophilia, including allergic diseases and parasitic infection, and signs or symptoms or both of organ involvement by eosinophilic infiltration. These defining criteria were used to identify patients with HES for many years. The clinical features of HES, as described in earlier case series [1,9-11], are summarized in Table 1. Throughout the years, HES has been reported to be more common in men compared with women, with a male to female ratio as high as nine to one [1]. Most cases have been described in adults, with ages at diagnosis often between 20 and 50 years [1,6,11], although pediatric cases of HES also occur [12,13].

\section{Modern definition and classification scheme of hypereosinophilic syndromes}

Contemporary experience related to the causes and management of HES patients have prompted an updating of the original diagnostic criteria proposed by Chusid et al. [5]. First, the need for a 6-month duration of eosinophilia [7], designed to exclude short-term episodes of eosinophilia, has been abandoned. For some patients, significant morbidity may arise if treatment is delayed until the 6-month time requirement is met. Therefore, patients can be considered to have HES without waiting for the 6-month time requirement if Chusid's second and third criteria are also met, and diagnostic testing and especially therapeutic interventions can be initiated based on clinical needs [4,14].

A second issue not treated in the earlier criteria of Chusid et al. was how to consider nominally organ specific eosinophilic diseases such as the acute and chronic eosinophilic pneumonias and EGIDs. Many of these diseases satisfied the early criteria of Chusid et al. for HES but often did not have the systemic complications seen in many with HES. At times, the organ specific eosinophilic diseases, often idiopathic, were difficult to exclude as premonitory presentations of more systemic eosinophilic disorders (e.g., HES or CSS).

These issues were discussed at an international workshop on eosinophilic diseases convened in May 2005 in Bern, Switzerland, and consensus opinions from the workshop were published in 2006 [4]. The more encompassing plural term of HESs was used with the intent 
of capturing all of the heterogeneous presentations of HES. The criteria for HESs presented in the workshop report differed from the original Chusid's criteria in that the 6-month time requirement was eliminated: eosinophils more than $1500 / \mu 1$; persistent eosinophilia or endorgan damage/dysfunction or both; and exclusion of secondary causes of eosinophilia. The breadth of HES was then subcategorized into the following categories: 'myeloproliferative variants (M-HES)', 'lymphocytic variants (L-HES)', 'familial eosinophilia', 'undefined forms of HES', 'overlap eosinophilic diseases', and 'eosinophil-associated diseases.'

Recognition of the myeloproliferative and lymphocytic variants of HES (considered below) provides an etiologic understanding for the nature of the hypereosinophilia. The relative frequencies of these variants as causes of HES are not yet clear and differ among referral centers [5]. As yet, most patients with HES lack etiologic understanding for their hypereosinophilia and fall in the subcategory of 'complex undefined HES'. This subcategory includes those with symptomatic organ involvement associated with eosinophilia and represents the majority of HES patients seen in many referral centers. Another subcategory of 'benign undefined HES' includes patients in whom elevated blood eosinophilia is not associated with evidence of organ involvement. Such patients would not satisfy the early HES criteria requiring signs and symptoms of organ involvement; but neither the causes for the eosinophilia nor the natural history of such patients are as yet known. Individuals with eosinophilia associated with single organ system involvement (e.g. eosinophilic pneumonias, EGIDs) would be categorized within 'overlap eosinophilic diseases.' Other diseases at times associated with eosinophilia, including Churg-Strauss vasculitis, mastocytosis and others, would be encompassed in 'eosinophil-associated diseases.'

It is realized that such classification schemes of the HESs remain a work in progress, and changes and refinements will occur as more is learned about the biological mechanisms underlying the various heterogeneous HES subtypes. [4,5].

\section{Chronic eosinophilic leukemia and the myeloproliferative variants of hypereosinophilic syndrome}

Early in the history of eosinophilic disorders, some HES patients appeared to have an eosinophilic form of leukemia, with cytogenetic or molecular evidence of eosinophil clonality [15]. However, such clonality was not often seen using available diagnostic techniques in early HES case series [1,5,9,11]. Reports in the 1970s and 1980s noted that some HES patients presented with clinical and hematologic features suggestive of a myeloproliferative-type process. Such features including very high peripheral blood eosinophil counts (more than $100000 / \mu 1$ ), hepatosplenomegaly, presence of chromosomal abnormalities or circulating immature precursor cells, increased serum vitamin B12, elevated leukocyte alkaline phosphatase, anemia or thrombocytopenia or both predicted a worse outcome $[5,7,16,17]$. Chromosomal karyotyping of such patients rarely demonstrated a gross defect. However, a major breakthrough in diagnostics for HES occurred in 2003 with the recognition of an interstitial deletion on chromosome $4 q 12$ that leads to fusion of the FIP1-like 1 (FIP1L1) and platelet-derived growth factor receptor (PDGFR)a genes, with the fusion product encoding for a protein that has constitutive tyrosine kinase activity [18]. Such patients have very pronounced peripheral blood eosinophilia as well as the myeloproliferative features discussed above, and are now included in the subcategory of MHES [4,19,20*]. M-HES disease with the FIP1L1-PDGFRa fusion mutation is a form of chronic eosinophilic leukemia (CEL), as WHO criteria identify eosinophil clonality as the defining feature of CEL, and identification of the FIP1L1-PDGFRa fusion mutation establishes clonality $\left[19,20^{\bullet \bullet}\right.$. Analogous chromosomal mutations involving the fibroblast growth factor receptor or PDGFR $\beta$ can also be associated less commonly with 
hypereosinophilia [3]. Common clinical and hematologic features [5] of M-HES are as follows:

1. often FIP1L1-PDGFRa fusion gene mutation positive,

2. usually male,

3. dysplastic peripheral eosinophils,

4. elevated serum B12,

5. elevated serum tryptase,

6. anemia or thrombocytopenia or both,

7. hepatosplenomegaly,

8. increased bone marrow cellularity,

9. atypical/spindle-shaped mast cells in bone marrow,

10. myelofibrosis,

11. frequent imatinib response (known with FIP1L1-PDGFRa fusion),

12. often get cardiac involvement.

The 2005 workshop consensus [4] was that a patient with HES, in the absence of detectable FIPLI-PDGFRa (or related) chromosomal mutation or other evidence of eosinophil clonality, could be considered to fall under M-HES if four or more of the following eight features are present: presence of dysplastic eosinophils on peripheral blood smear, serum B12 level more than $1000 \mathrm{pg} / \mathrm{ml}$; serum tryptase at least $12 \mathrm{ng} / \mathrm{ml}$; anemia or thrombocytopenia or both; hepatosplenomegaly; bone marrow biopsy cellularity greater than $80 \%$; presence of dysplastic mast cells in the bone marrow (defined as $>25 \%$ of mast cells being spindle-shaped [21]); and myelofibrosis (presence of antireticulin antibody staining on bone marrow biopsy [21]).

Recent studies $\left[20^{\bullet}, 22\right]$ have looked at the presence of elevated serum tryptase and atypical bone marrow mast cells in M-HES, as well as the clinical overlap between M-HES and systemic mastocytosis. Although there can be overlap between HES and mastocytosis, HES patients are differentiated from mastocytosis by the fact that they do not have the somatic $c$ kit mutations that can be seen in mastocytosis [21]. The most common c-kit mutation seen in mastocytosis, the 'D816V' mutation, is unresponsive to treatment with imatinib $\left[19,20^{\circ}, 23\right]$.

\section{Lymphocytic variants of hypereosinophilic syndrome}

$\mathrm{CD} 4^{+} \mathrm{T}$ cells, especially of the Th2 subtype, are major sources of the eosinophilopoietic and eosinophil-activating cytokine, interelukin (IL)-5, as well as cytokines stimulating IgE production. Individuals with L-HES have an underlying T-cell disorder $[14,24,25]$. Since 1994, patients have been recognized who have T-cell clones capable of secreting elevated amounts of IL-5 [26-28]. The abnormal T-cell subpopulations often have aberrant surface phenotypes, often being $\mathrm{CD}^{-}{ }^{-} \mathrm{CD} 4^{+}$and less commonly being $\mathrm{CD} 3^{+} \mathrm{CD} 4^{-} \mathrm{CD} 8^{-}$[3]. Further investigation of the $\mathrm{CD}^{-}{ }^{-} \mathrm{CD} 4^{+}$aberrant $\mathrm{T}$-cell sub-populations revealed high expression of CD5 and loss of CD7 or CD27 expression on the T-cell populations in many cases [29]. The abnormal subsets also often demonstrate an activated (CD25 or HLA-DR ${ }^{+}$) memory $\left(\mathrm{CD} 45 \mathrm{RO}^{+}\right)$phenotype $[28,29]$. Accordingly, L-HES was defined as 'a primitive lymphoid disorder characterized by nonmalignant expansion of a T-cell population able to produce eosinophilopoietic cytokines (generally IL-5)' [3,14], with the T-cell population being identified by flow cytometry or reverse transcriptase (RT)-PCR for altered T-cell receptor usage or both [4]. Elevated IgE, IgM, and IgG can often be seen in L-HES, but these 
findings are not specific for L-HES [27-30]. Other common features of L-HES [5] are outlined as follows:

1. could be male or female with equal frequency,

2. FIP1L1-PDGFRa fusion gene mutation negative,

3. often increased serum IgE,

4. may have increased serum $\operatorname{IgG}, \operatorname{IgM}$,

5. may have increased serum IL-5,

6. may have increased serum TARC (thymus and activation-regulated chemokine),

7. abnormal or clonal T-cell populations may be detected or both,

8. rarely have cardiac involvement,

9. frequent cutaneous involvement,

10. frequent history of atopy,

11. usually good response to glucocorticoids.

\section{Contemporary diagnosis and treatment of categories of hypereosinophilic syndrome}

The following paragraphs highlight the major issues that have been covered in the literature on HES over the past 1-2 years.

\section{Cardiovascular complications of hypereosinophilic syndrome}

In eosinophilic disorders, including those secondary to parasitic infections and to cytokine therapies, eosinophil-mediated damage to the endocardium and myocoardium may occur. The cardiac manifestations of HES are more likely to occur with M-HES (particularly when FIP1L1-PDGFRa positive) compared with the other HES subtypes $\left[4,20^{\circ}, 31^{\circ}\right]$, for reasons that remain unknown [5]. In potential M-HES and other forms of HES, assays of serum troponins are now recognized to provide sensitive, early indications of eosinophil-mediated endomyocardial damage in forms of HES and secondary hypereosinophilia [32*0]. Elevated troponins in concert with hypereosinophilia should prompt consideration of therapies for the hyperesoinophilia.

\section{Myeloproliferative variants of hypereosinophilic syndrome: diagnosis and treatment}

Patients with HES, especially those with clinical and hematologic features compatible with M-HES, should be evaluated with RT-PCR or fluorescence in-situ hybridization (FISH) for the presence of the FIP1L1-PDGFRa mutation. If FIP1L1-PDGFRa mutations are demonstrable or patients present with other features of M-HES, therapy with imatinib is indicated. Most M-HES patients are unresponsive to glucocorticosteroid therapy. Based on the high rate of response of FIP1L1-PDGFRa M-HES to imatinib, this drug is the first-line agent for FIP1L1-PDGFRa M-HES [33,34]. Dosing of imatinib is best based not on levels of eosinophilia or clinical symptoms, but on RT-PCR-based evaluations of suppression of FIP1L1-PDGFRa transcripts $\left[35^{\circ}, 36\right]$. There may be reversal of hematological features of M-HES in patients who are responsive to imatinib, including reduction of serum tryptase, molecular remission of FIP1L1-PDGFRa positivity, disappearance of the bone marrow atypical spindle-shaped mast cells, and improvement of myelofibrosis [33,37]. Trials of imatinib therapy are warranted on M-HES patients without the FIP1L1-PDGFRa mutation [33,34]. Newer tyrosine-receptor kinase inhibitors and allogenic bone marrow transplantation may be considered for those unresponsive to imatinib. 


\section{Lymphocytic variants of hypereosinophilic syndrome, complex undefined hypereosinophilic syndrome, and other forms of hypereosinophilic syndrome}

To ascertain a diagnosis of a L-HES variant of HES, T-cell immunophenotyping by multicolor flow cytometry or assays of T-cell receptor (TCR) clonality or both should be performed on HES patients. L-HES patients are at risk of developing T-cell lymphomas [3]. For L-HES, complex undefined HES and other forms of HES, the principal therapeutic has been glucocorticosteroids.

For L-HES, though it has been speculated that interferon (IFN)a may have benefit in L-HES by reducing the activity and cytokine production of abnormal T-cell clones [38], IFNa may inhibit the spontaneous apoptosis of $\mathrm{CD}^{-}{ }^{-} \mathrm{CD} 4^{+} \mathrm{T}$ cells [39], so it is theoretically possible that monotherapy with IFNa could enhance the transformation of L-HES to lymphoma $[3,14]$. In conjunction with glucocorticosteroids, IFNa may be used as a steroid-sparing agent [40].

For undefined complex subcategories of HES, steroids, perhaps in conjunction with hydroxyurea and IFNa (as steroid-sparing agents) may be used, but specific data are lacking.

\section{Candidate future therapies for nonmyeloproliferative variants of hypereosinophilic syndrome}

The most prominently studied anti-cytokine therapy for HES has been with monoclonal antibodies to IL-5. One such antibody, mepolizumab, was recently reported to be both safe and highly effective as a corticosteroid-sparing therapy for non-FIP1L1-PDGFRa HES patients $\left[41^{\bullet}, 42^{\bullet}\right]$.

In theory, other therapies might be able to modulate the abnormal activity of aberrant T-cell populations, such as alemtuzumab (monoclonal antibody to CD52) [43,44], cyclosporine A, and monoclonal antibodies to IL-2R-a, but have not undergone significant study for this purpose $[14,43,44]$.

\section{Conclusion}

A contemporary consideration has expanded the range of eosinophilic disorders that are included within the spectrum of HESs. Based on recent advances in molecular and genetic diagnostic techniques and increasing experience with differences in clinical features and prognosis, subtypes have been defined, including M-HES and L-HES. Other HES subtypes, including the likely most common type of 'complex undefined HES', await future insights into their underlying pathophysiology.

\section{References and recommended reading}

Papers of particular interest, published within the annual period of review, have been highlighted as:

- of special interest

•• of outstanding interest

Additional references related to this topic can also be found in the Current World Literature section in this issue (p. 61).

1. Weller PF, Bubley GJ. The idiopathic hypereosinophilic syndrome. Blood. 1994; 83:2759-2779.

[PubMed: 8180373] 
2. Bain BJ. Hypereosinophilia. Curr Opin Hematol. 2000; 7:21-25. [PubMed: 10608500]

3. Roufosse F, Cogan E, Goldman M. The hypereosinophilic syndrome revisited. Annu Rev Med. 2003; 54:169-184. [PubMed: 12525672]

4. Klion AD, Bochner BS, Gleich GJ, et al. The hypereosinophilic syndromes working group. Approaches to the treatment of hypereosinophilic syndromes: a workshop summary report. J Allergy Clin Immunol. 2006; 117:1292-1302. [PubMed: 16750989]

5. Sheikh J, Weller PF. Clinical overview of hypereosinophilic syndromes. Immunol Allergy Clin North Am. 2007; 27:333-355. [PubMed: 17868853]

6. Spry, C. A comprehensive review and guide to the scientific and medical literature. Oxford, UK: Oxford Medical Publications; 1988. Eosinophils.

7. Chusid MJ, Dale DC, West BC, Wolff SM. The hypereosinophilic syndrome: analysis of fourteen cases with review of the literature. Medicine (Baltimore). 1975; 54:1-27. [PubMed: 1090795]

8. Hardy WR, Anderson RE. The hypereosinophilic syndromes. Ann Intern Med. 1968; 68:1220-1229. [PubMed: 5653621]

9. Lefebvre C, Bletry O, Degoulet P, et al. Prognostic factors of hypereosinophilic syndrome. Study of 40 cases. Ann Med Interne (Paris). 1989; 140:253-257. [PubMed: 2675714]

10. Spry CJ, Davies J, Tai PC, et al. Clinical features of fifteen patients with the hypereosinophilic syndrome. Q J Med. 1983; 52:1-22. [PubMed: 6878618]

11. Fauci AS, Harley JB, Roberts WC, et al. NIH conference. The idiopathic hypereosinophilic syndrome. Clinical, pathophysiologic, and therapeutic considerations. Ann Intern Med. 1982; 97:78-92. [PubMed: 7046556]

12. Katz HT, Haque SJ, Hsieh FH. Pediatric hypereosinophilic syndrome (HES) differs from adult HES. J Pediatr. 2005; 146:134-136. [PubMed: 15644839]

13. Rives S, Alcorta I, Toll T, et al. Idiopathic hypereosinophilic syndrome in children: report of a 7year-old boy with FIP1L1-PDGFRA rearrangement. J Pediatr Hematol Oncol. 2005; 27:663-665. [PubMed: 16344672]

14. Roufosse F, Goldman M, Cogan E. Hypereosinophilic syndrome: lymphoproliferative and myeloproliferative variants. Semin Respir Crit Care Med. 2006; 27:158-170. [PubMed: 16612767]

15. Ackerman GA. Eosinophilic leukemia: a morphologic and histochemical study. Blood. 1964; 24:372-388. [PubMed: 14220780]

16. Dale DC, Hubert RT, Fauci A. Eosinophil kinetics in the hypereosinophilic syndrome. J Lab Clin Med. 1976; 87:487-495. [PubMed: 1249478]

17. Schooley RT, Flaum MA, Gralnick HR, Fauci AS. A clinicopathologic correlation of the idiopathic hypereosinophilic syndrome. II. Clinical manifestations. Blood. 1981; 58:1021-1026. [PubMed: 7197566]

18. Cools J, DeAngelo DJ, Gotlib J, et al. A tyrosine kinase created by fusion of the PDGFRA and FIP1L1 genes as a therapeutic target of imatinib in idiopathic hypereosinophilic syndrome. N Engl J Med. 2003; 348:1201-1214. [PubMed: 12660384]

19. Bain BJ. Relationship between idiopathic hypereosinophilic syndrome, eosinophilic leukemia, and systemic mastocytosis. Am J Hematol. 2004; 77:82-85. [PubMed: 15307112]

20••. Bain BJ, Fletcher SH. Chronic eosinophilic leukemias and the myeloproliferative variant of the hypereosinophilic syndrome. Immunol Allergy Clin North Am. 2007; 27:377-388. An excellent review of the contemporary thinking of overlap between chronic eosinophilic leukemias and HES, with particular attention on the FIP1L1-PDGFRa mutation positive variant of M-HES. [PubMed: 17868855]

21. Klion AD, Noel P, Akin C, et al. Elevated serum tryptase levels identify a subset of patients with a myeloproliferative variant of idiopathic hypereosinophilic syndrome associated with tissue fibrosis, poor prognosis, and imatinib responsiveness. Blood. 2003; 101:4660-4666. [PubMed: 12676775]

22. Ackerman SJ, Bochner BS. Mechanisms of eosinophilia in the pathogenesis of hypereosinophilic disorders. Immunol Allergy Clin North Am. 2007; 27:357-375. [PubMed: 17868854] 
23. Pardanani A, Brockman SR, Paternoster SF, et al. FIP1L1-PDGFRA fusion: prevalence and clinicopathologic correlates in 89 consecutive patients with moderate to severe eosinophilia. Blood. 2004; 104:3038-3045. [PubMed: 15284118]

24. Raghavachar A, Fleischer S, Frickhofen N, et al. T lymphocyte control of human eosinophilic granulopoiesis. Clonal analysis in an idiopathic hypereosinophilic syndrome. J Immunol. 1987; 139:3753-3758. [PubMed: 3500229]

25. Schrezenmeier H, Thome SD, Tewald F, et al. Interleukin-5 is the predominant eosinophilopoietin produced by cloned T lymphocytes in hypereosinophilic syndrome. Exp Hematol. 1993; 21:358365. [PubMed: 8425573]

26. Cogan E, Schandene L, Crusiaux A, et al. Brief report: clonal proliferation of type 2 helper T cells in a man with the hypereosinophilic syndrome. N Engl J Med. 1994; 330:535-538. [PubMed: 8302319]

27. Roufosse F, Cogan E, Goldman M. Recent advances in pathogenesis and management of hypereosinophilic syndromes. Allergy. 2004; 59:673-689. [PubMed: 15180753]

28. Simon HU, Plotz SG, Dummer R, Blaser K. Abnormal clones of T cells producing interleukin-5 in idiopathic eosinophilia. N Engl J Med. 1999; 341:1112-1120. [PubMed: 10511609]

29. Roufosse F, Schandene L, Sibille C, et al. Clonal Th2 lymphocytes in patients with the idiopathic hypereosinophilic syndrome. Br J Haematol. 2000; 109:540-548. [PubMed: 10886202]

30. Griffin JH, Leung J, Bruner RJ, et al. Discovery of a fusion kinase in EOL-1 cells and idiopathic hypereosinophilic syndrome. Proc Natl Acad Sci U S A. 2003; 100:7830-7835. [PubMed: 12808148]

31 • Ogbogu PU, Rosing DR, Horne MK 3rd. Cardiovascular manifestations of hypereosinophilic syndromes. Immunol Allergy Clin North Am. 2007; 27:457-475. Comprehensive review of the forms of cardiovascular involvement in HES, with discussion of implications for therapy. [PubMed: 17868859]

32••. Gertz MA. Troponin in hematologic oncology. Leuk Lymphoma. 2008; 49:194-203. This is the first review to discuss the role of measurement of troponin level in blood to assess myocardial involvement in HES. [PubMed: 18231905]

33. Klion AD. Approach to the therapy of hypereosinophilic syndromes. Immunol Allergy Clin North Am. 2007; 27:551-560. [PubMed: 17868864]

34. Simon HU, Cools J. Novel approaches to therapy of hypereosinophilic syndromes. Immunol Allergy Clin North Am. 2007; 27:519-527. [PubMed: 17868862]

35••. Klion AD, Robyn J, Maric I, et al. Relapse following discontinuation of imatinib mesylate therapy for FIP1L1/PDGFRA-positive chronic eosinophilic leukemia: implications for optimal dosing. Blood. 2007; 110:3552-3556. One of the first studies to discuss optimal dosing of imatinib for FIP1L1/PDGFRA-positive CEL/HES, which will likely lead to further studies along these lines. [PubMed: 17709602]

36. Helbig G, Stella-Holowiecka B, Majewski M, et al. A single weekly dose of imatinib is sufficient to induce and maintain remission of chronic eosinophilic leukaemia in FIP1L1-PDGFRAexpressing patients. Br J Haematol. 2008; 141:200-204. [PubMed: 18307562]

37. Klion AD, Robyn J, Akin C, et al. Molecular remission and reversal of myelofibrosis in response to imatinib mesylate treatment in patients with the myeloproliferative variant of hypereosinophilic syndrome. Blood. 2004; 103:473-478. [PubMed: 14504092]

38. Schandene L, Del Prete GF, Cogan E, et al. Recombinant interferon-alpha selectively inhibits the production of interleukin-5 by human CD4+ T cells. J Clin Invest. 1996; 97:309-315. [PubMed: 8567949]

39. Schandene L, Roufosse F, de Lavareille A, et al. Interferon alpha prevents spontaneous apoptosis of clonal Th2 cells associated with chronic hypereosinophilia. Blood. 2000; 96:4285-4292. [PubMed: 11110703]

40. Roufosse FE, Goldman M, Cogan E. Hypereosinophilic syndromes. Orphanet J Rare Dis. 2007; 2:37. [PubMed: 17848188]

41••. Rothenberg ME, Klion AD, Roufosse FE, et al. Treatment of patients with the hypereosinophilic syndrome with mepolizumab. N Engl J Med. 2008; 358:1215-1228. Report of the most 
comprehensive study of a monoclonal antibody to IL-5, which describes efficacy as a steroidsparing agent for non FIP1L1/PDGFRA HES. [PubMed: 18344568]

42•. Stein ML, Villanueva JM, Buckmeier BK, et al. Anti-IL-5 (mepolizumab) therapy reduces eosinophil activation ex vivo and increases IL-5 and IL-5 receptor levels. J Allergy Clin Immunol. 2008; 121:1473-1483. 1483 e1471-1474. A groundbreaking study, shedding light on the mechanisms of action and efficacy of this monoclonal antibody to IL-5. [PubMed: 18410960]

43. Pitini V, Teti D, Arrigo C, Righi M. Alemtuzumab therapy for refractory idiopathic hypereosinophilic syndrome with abnormal T cells: a case report. Br J Haematol. 2004; 127:477. [PubMed: 15566349]

44. Sefcick A, Sowter D, DasGupta E, et al. Alemtuzumab therapy for refractory idiopathic hypereosinophilic syndrome. Br J Haematol. 2004; 124:558-559. [PubMed: 14984510] 
Table 1

Traditionally described clinical features of hypereosinophilic syndrome

\begin{tabular}{|c|c|}
\hline Organ system involvement (frequency) & Specific features that may be seen \\
\hline \multirow[t]{5}{*}{ Hematologic (100\%) } & Eosinophilia (by definition) \\
\hline & Anemia \\
\hline & Thrombocytosis \\
\hline & Thrombocytopenia \\
\hline & Lymphadenopathy \\
\hline \multirow[t]{4}{*}{ Cardiovascular (58\%) } & Endomyocardial damage or necrosis or both \\
\hline & Intramural thrombi \\
\hline & Endomyocardial fibrosis \\
\hline & Congestive heart failure \\
\hline \multirow[t]{3}{*}{ Cutaneous $(56 \%)$} & Urticaria \\
\hline & Angioedema \\
\hline & Pruritic papules or nodules or both \\
\hline \multirow[t]{3}{*}{ Neurologic (54\%) } & Generalized CNS symptoms \\
\hline & Peripheral neuropathies (variable patterns described) \\
\hline & Thromboembolic neurologic phenomena \\
\hline \multirow[t]{3}{*}{ Pulmonary (49\%) } & Dry cough \\
\hline & Nonspecific infiltrates \\
\hline & Pulmonary fibrosis \\
\hline \multirow[t]{2}{*}{ Spleen (43\%) } & Splenomegaly \\
\hline & Hypersplenism \\
\hline \multirow[t]{2}{*}{ Liver (30\%) } & Chronic active hepatitis \\
\hline & Budd-Chiari syndrome \\
\hline \multirow[t]{3}{*}{ Gastrointestinal (23\%) } & Eosinophilic inflammatory esophagitis \\
\hline & Eosinophilic gastroenteritis \\
\hline & Eosinophilic colitis \\
\hline \multirow[t]{2}{*}{ Ocular (23\%) } & Choroidal abnormalities \\
\hline & Nonspecific vision changes \\
\hline
\end{tabular}

The left column includes the percentage of patients who have involvement of each organ system. Adapted from [1,9-11]. 